American J. of Engineering and Applied Sciences 3 (2): 396-402, 2010

ISSN 1941-7020

(C) 2010 Science Publications

\title{
Influence of Process Parameters on Electrical Discharge Machined Job Surface Integrity
}

\author{
A.K.M. Asif Iqbal and Ahsan Ali Khan \\ Department of Manufacturing and Materials Engineering, Faculty of Engineering, \\ International Islamic University, P.O. Box 10, 50728 Kuala Lumpur, Malaysia
}

\begin{abstract}
Problem statement: Electrical Discharge Machining (EDM) is the most widely used non conventional machining process for removing material from workpiece by means of a series of repeated electric discharges. Electrical Discharge milling (ED-milling) is an emerging technology where a cylindrical tool electrode follows a programmed path in order to obtain the desired shape of a part. During machining of metals by EDM process, a large amount of heat is generated for which the surface characteristics of the metals are affected. This phenomenon is unavoidable but this can be controlled by suitable selection of the process parameters. Though in most of the cases only electrical parameters are chosen but non electrical parameters also play significant role in the area of surface integrity of the machined surface. The present study emphasized to establish a comprehensive analysis of surface integrity, including the micro cracks, recast layer thickness and material migration by combining both electrical and non electrical process parameters under a wide range of machining condition. Approach: In this research, experiment was designed by using design expert software (DOE). Response Surface Methodology (RSM) was used for designing the experiment. The process parameters varied in the present study were the rotational speed of the electrode $(\mathrm{N})$, Voltage $(\mathrm{V})$ and feed rate (f). Stainless steel AISI 304 was chosen as work material while a copper electrode was used for EDM milling operation. The EDM milling operations were performed on EDM machine mikrotools integrated multi process machine tools DT 110. In this research, Scanning Electron Microscope (SEM) was used to investigate the effect of machining parameters on recast layer thickness, micro cracks on the machined surface as well as the percentage of material migration on the workpiece surface. Results: Electrode rotation reduces recast layer thickness of about $16.58 \%$ than that of stationary electrode with same voltage and feed rate. Moreover, it was observed that migration of $\mathrm{C}$ and $\mathrm{Cu}$ on the workpiece surface reduces 8.8 and $60 \%$ respectively when using rotary electrode instead of stationary electrode with same parameters setting. Conclusion: These results indicated that voltage and rotary speed of electrode significantly affect various criteria of surface integrity. Electrode rotation helped to reduce micro cracks, recast layer thickness as well as migration of material became less when rotary electrode is used. Besides, the combination of reasonably low voltage and high rpm reduced micro cracks, recast layer thickness and minimized the surface contamination on workpiece surface during EDM milling of stainless steel.
\end{abstract}

Key words: EDM milling, recast layer thickness, micro crack, material migration

\section{INTRODUCTION}

Electrical Discharge Machining (EDM) is a thermoelectric process that erodes workpiece material by series of discrete but controlled electrical sparks between the workpiece and electrode immersed in a dielectric fluid. It has been proven to be especially valuable in the machining of super-tough, electrically conductive materials such as the new space-age alloys. These materials would have been difficult to machine by conventional methods, but EDM has made it relatively simple to machine intricate shapes that would be impossible to produce with conventional cutting tools. In EDM process, the shapes of mold cavities are directly copied from that of tool electrodes, so timeconsuming preparation work must be done on the fabrication of the corresponding tool electrodes. When the shape of the expected cavities changes or the wear of the tool electrodes exceeds a certain limit, they must be remade, wasting both time and money. To deal with this problem, EDM milling is the useful process where a cylindrical tool electrode follows a programmed path

Corresponding Author: A.K.M. Asif Iqbal, Department of Manufacturing and Materials Engineering, Faculty of Engineering, International Islamic University, P.O. Box 10, 50728 Kuala Lumpur, Malaysia 
in order to obtain the desired shape of a part (Bayramoglu and Duffill, 1994; Yu et al., 1998). Since, standard tool electrodes are used, the preparation time for EDM milling is dramatically reduced.

It is found from previous studies that the EDM process changes not only the surface of the workpiece material but also the subsurface (Kruth et al., 1995). The EDM surface is made up of three distinctive layers consisting of recast layer/white layer, heat affected zone and unaffected parent metal (Ho and Newman, 2003). Since the recast layer is the topmost layer exposed to the environment, it exerts a great influence on the surface properties of the workpiece. This layer is formed by the un-expelled molten metal solidifying in the crater. The molten metal is rapidly quenched by the dielectric. Several authors discovered the presence of micro-cracks in this very hard brittle layer. If this layer is too thick or is not reduced or removed by polishing, the effects of this layer can cause premature failure of the part in some applications (Kumar et al., 2008). Therefore, reduction of recast layer thickness is one of the major challenges for researchers to improve surface integrity as well as EDM performance. Moreover, during EDM, the chemical composition of the workpiece and electrode changes due to material migration between the workpiece and electrode. This migration of material causes the behavioral changes of the workpiece and electrode (Ho and Newman, 2003). Since EDM was developed, much theoretical and experimental work has been done to identify the basic processes involved and the performance of EDM process. In spite of significant progress in this technique and marked improvement in surface integrity after machining, some technical problems remain unsolved. In many cases, as in tools, dies and aerospace components, severe pressure and thermal loadings are encountered. To avoid possible failures arising from the surface defects of EDMed components, it is vital that there should be an adequate understanding of the nature and extent of surface damage imparted under various machining conditions.

Significant findings have been made by many researchers to improve surface integrity. Abu Zeid (1997) found that intense heat generated associated with each discharge during machining results in local severe temperature gradients in the machined surface on cessation of the discharge, the surface layers cool quickly and develop a residual tensile stress that is often sufficient to produce cracks in the machined surfaces. Lee and Tai (2003) further added that the structure of this thermally affected layer is quite different from the parent material and the defects within it such as voids, cracks and induced stress cause an overall deterioration of the component's mechanical properties. Lee et al. (1988) showed among the surface defects, cracking is the most significant since it leads to reduction in the material resistance to fatigue and corrosion, especially under tensile loading condition. Lee et al. (1990) demonstrated that cracks usually appear in brittle recast layer, may lead to the failure of the EDMed product, particularly under conditions of fatigue and impact loading. Consequently, if the quality of EDMed product is to be improved, it is essential to develop an in depth understanding of the relationship between the predominant EDM machining parameters and the resulting machined surface integrity, i.e., recast layer thickness, surface crack density and material migration. From the available research findings, it has been seen that electrical parameters like peak current, pulse-on duration and voltage have the most prominent influence on EDM surface integrity (Ramasawmy and Blunt, 2004; Ho and Newman, 2003). However few research works were conducted which explained the effect of non-electrical process parameters like rotational speed of electrode, rotational speed of workpiece, flushing of dielectric fluid and feed rate on EDM surface integrity (Caydas and Hascalik, 2007; Bhattacharyya et al., 2007). Therefore, this study attempts to establish a comprehensive analysis of surface integrity, including the micro cracks, recast layer thickness and material migration by combining both electrical and non electrical process parameters under a wide range of machining condition.

\section{MATERIALS AND METHODS}

Experimental set-up: In this research, experiment was designed by using design expert software (DOE). Response Surface Methodology (RSM) was used for designing the experiment. The process parameters varied in the present study were the rotational speed of the electrode $(\mathrm{N})$, Voltage $(\mathrm{V})$ and feed rate (f) while other factors such as dielectric fluid pressure, polarity of the electrode and capacitance maintained constant. The three machining factors and their selected levels are shown in Table 1.

A rectangular piece of stainless steel AISI 304 was chosen as work material while a cylindrical copper electrode was used for EDM milling operation. The dimensions of workpiece and electrode were $100 \times 30 \times 8 \mathrm{~mm}$ and $70 \mathrm{~mm} \times \varphi 5 \mathrm{~mm}$ respectively.

Table 1: Factors and levels selected for the experiments

\begin{tabular}{llll}
\hline & & Levels & \\
& Factors & -1 & +1 \\
\hline A & Rotational speed of electrode, N (RPM) & 1000 & 1500 \\
B & Voltage, V $(\mathrm{V})$ & 80 & 120 \\
$\mathrm{C}$ & Feed rate, $\mathrm{f}\left(\mu \mathrm{m} \mathrm{sec}^{-1}\right)$ & 4 & 6 \\
\hline
\end{tabular}


Am. J. Engg. \& Applied Sci., 3 (2): 396-402, 2010

Table 2: Central Composite Design (CCD) matrix and results of recast layer thickness and material migration

\begin{tabular}{|c|c|c|c|c|c|c|c|}
\hline \multirow[b]{2}{*}{ Run } & \multirow[b]{2}{*}{ Block } & \multirow[b]{2}{*}{$\begin{array}{l}\text { Voltage } \\
\text { (V) }\end{array}$} & \multirow[b]{2}{*}{$\begin{array}{l}\text { Rotational speed } \\
\text { of electrode (rpm) }\end{array}$} & \multirow[b]{2}{*}{$\begin{array}{l}\text { Feed rate } \\
\left(\mu \mathrm{mec}^{-1}\right)\end{array}$} & \multirow[b]{2}{*}{$\begin{array}{l}\text { Recast layer } \\
\text { thickness }\end{array}$} & \multicolumn{2}{|c|}{$\begin{array}{l}\text { Material migration from } \\
\text { electrode to workpiece }\end{array}$} \\
\hline & & & & & & $\mathrm{C}(\%)$ & $\mathrm{Cu}(\%)$ \\
\hline$\overline{1}$ & Block 1 & 120.00 & 1500.00 & 4.00 & 8.43 & 4.23 & 0.24 \\
\hline 2 & Block 1 & 100.00 & 1250.00 & 5.00 & 6.95 & 4.39 & 0.18 \\
\hline 3 & Block 1 & 120.00 & 1000.00 & 4.00 & 9.00 & 4.36 & 0.23 \\
\hline 4 & Block 1 & 80.00 & 1500.00 & 6.00 & 5.91 & 4.15 & 0.12 \\
\hline 5 & Block 1 & 80.00 & 1000.00 & 6.00 & 6.45 & 4.19 & 0.19 \\
\hline 6 & Block 1 & 120.00 & 1000.00 & 6.00 & 8.76 & 4.32 & 0.23 \\
\hline 7 & Block 1 & 100.00 & 1250.00 & 5.00 & 6.74 & 4.42 & 0.18 \\
\hline 8 & Block 1 & 100.00 & 1250.00 & 5.00 & 7.14 & 4.46 & 0.17 \\
\hline 9 & Block 1 & 100.00 & 1250.00 & 5.00 & 6.98 & 4.44 & 0.15 \\
\hline 10 & Block 1 & 120.00 & 1500.00 & 6.00 & 8.26 & 4.28 & 0.18 \\
\hline 11 & Block 1 & 80.00 & 1500.00 & 4.00 & 5.70 & 4.22 & 0.12 \\
\hline 12 & Block 1 & 80.00 & 1000.00 & 4.00 & 6.31 & 4.30 & 0.14 \\
\hline 13 & Block 2 & 100.00 & 1250.00 & 6.68 & 6.89 & 4.48 & 0.2 \\
\hline 14 & Block 2 & 100.00 & 1250.00 & 5.00 & 7.19 & 4.32 & 0.19 \\
\hline 15 & Block 2 & 133.64 & 1000.00 & 5.00 & 8.12 & 4.60 & 0.26 \\
\hline 16 & Block 2 & 100.00 & 1670.45 & 5.00 & 6.83 & 4.33 & 0.22 \\
\hline 17 & Block 2 & 100.00 & 1250.00 & 5.00 & 6.78 & 4.47 & 0.21 \\
\hline 18 & Block 2 & 100.00 & 1250.00 & 3.32 & 6.53 & 4.22 & 0.20 \\
\hline 19 & Block 2 & 100.00 & 829.55 & 5.00 & 7.02 & 4.51 & 0.22 \\
\hline 20 & Block 2 & 66.36 & 1250.00 & 5.00 & 7.58 & 4.21 & 0.13 \\
\hline
\end{tabular}

The EDM milling operations were performed on EDM machine Mikrotools Integrated Multi Process Machine Tools DT 110. In this research, Scanning Electron Microscope (SEM) model Jeol JSM-5600 was used to investigate the effect of machining parameters on recast layer thickness, micro cracks on the machined surface as well as the percentage of material migration on the workpiece surface. The EDMed workpiece was cut into smaller size of $10 \times 10 \mathrm{~mm}$ square in order to be placed in the SEM. The cut surfaces were then sanded with the emery papers of reducing grain sizes. This was followed by polishing with alumina $\left(\mathrm{Al}_{2} \mathrm{O}_{3}\right)$ and the machined test pieces were thoroughly washed with acetone using Ultra Sonic Cleaner. The effect of rotary motion of electrode was investigated first. The surface was EDMed with stationary electrode with parameter setting of V $80 \mathrm{~V}$ and $\mathrm{f} 4 \mu \mathrm{m} \mathrm{sec}{ }^{-1}$ and with rotary electrode with the same parameter settings of $\mathrm{V}$ and $\mathrm{f}$ but $\mathrm{N}$ used $500 \mathrm{rpm}$ and results of both the cases were compared. For further analysis to investigate the combined effect of machining parameters selected for the experiment on recast layer thickness, micro cracks and material migration, all the surfaces EDMed with different combination of process parameters provided by DOE were examined thoroughly and the result is presented in Table 2.

\section{RESULTS AND DISCUSSION}

Analysis of micro crack on workpiece surface: Among the surface defects cracking is the most significant since it leads to a reduction in the fatigue and corrosion resistance of the material especially under tensile loading condition. In this experiment, micro cracks were observed thoroughly. Micro cracks for workpiece were revealed at high magnification using SEM microscope. Observation on the surfaces of the workpiece EDMed with stationary electrode revealed more cracks (Fig. 1a), than that of the workpiece surface EDMed with rotary electrode (Fig. 1b). Moreover, the minimum number of cracks was found in the parameter setting of $\mathrm{V} 80 \mathrm{~V}, \mathrm{~N}$ $1500 \mathrm{rpm}$ and $\mathrm{f} 6 \mu \mathrm{m} \mathrm{sec} \mathrm{se}^{-1}$ (Run 4 of Table 2; Fig. 1c), whereas, the maximum number of cracks observed in the parameter setting of $\mathrm{V} 120 \mathrm{~V}, \mathrm{~N}$ $1000 \mathrm{rpm}$ and $\mathrm{f} 6 \mu \mathrm{m} \mathrm{sec}^{-1}$ (Run 6 of Table 2; Fig. 1d).

It is observed that number of cracks in the workpiece surface reduces when EDM takes place with rotary electrode. It is also observed that number of cracks in the EDMed surface decreases with increase in rpm. This is because; flushing rate becomes high at high rpm which removes eroded particles from the gap and reduces the recast layer thickness. As crack density is linearly related with recast layer thickness; the reduction of recast layer at high rpm helps to reduce the crack formation on the workpiece surface. Moreover, uniform temperature distribution can be achieved by increase in rpm which helps to obtain fewer cracks. On contrary, the number of crack increases with increase in voltage. When the voltage is increased from $80 \mathrm{~V}$ to $120 \mathrm{~V}$, discharge strikes the surface more intensely. 


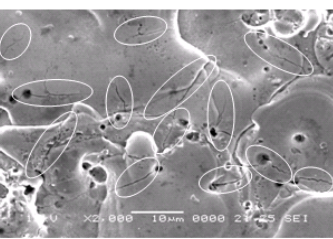

(a)

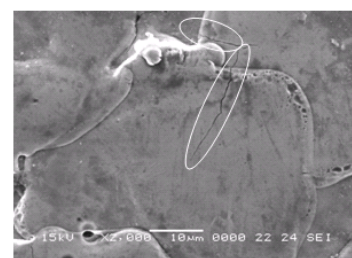

(c)

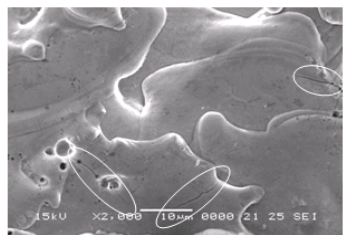

(b)

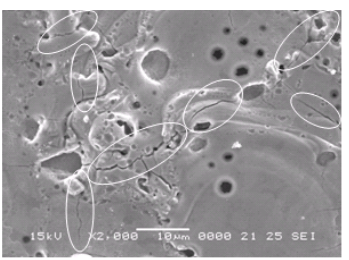

(d)

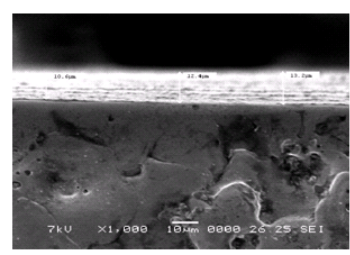

(a)

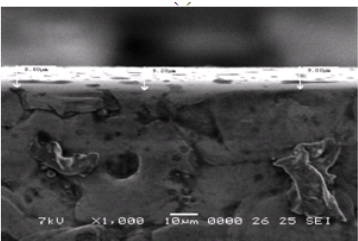

(c)

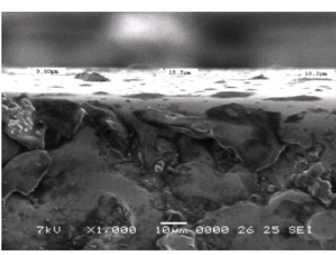

(b)

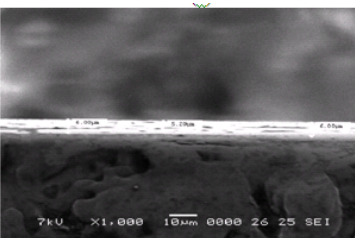

(d)
Fig. 1: SEM photographs of microcracks on workpiece surface with: (a) stationary electrode; (b) rotary electrode; (c) combination of $80 \mathrm{~V}, 1500 \mathrm{rpm}$ and $6 \mu \mathrm{m} \mathrm{sec} \mathrm{se}^{-1}$; (d) combination of $120 \mathrm{~V}$, $1000 \mathrm{rpm}$ and $6 \mu \mathrm{m} \mathrm{sec}{ }^{-1}$

This results in more spark energy to be accumulated in the workpiece as a result of higher thermal loading, this consequently results in more crack in the workpiece surface. The effect of crack becomes more pronounced as voltage increases.

Analysis of recast layer thickness: Formation of recast layer is as a result of molten materials that are not completely flush away by dielectric fluid from the workpiece surface. These molten materials solidify during cooling process and deposited on the workpiece. In this experiment, the recast layer thickness of the workpiece was first investigated using stationary and rotary electrode with same voltage and feed rate parameters of $80 \mathrm{~V}$ and $4 \mu \mathrm{m} \mathrm{sec}{ }^{-1}$ respectively as the previous analysis of microcracks. After that the combined effect of process parameters on recast layer thickness were examined by analyzing all surfaces which were EDMed with different combination of process parameters provided by DOE. Three measurements were taken across the thickness of each layer and the results are shown in Table 2.

SEM views of recast layer thickness of workpiece EDMed with stationary and rotary electrode (Fig. 2a and $b$ ), revealed that recast layer formed on the surface EDMed with rotary electrode (Fig. 2b) is thinner than that of the surface EDMed with stationary electrode (Fig. 2a). The recorded thickness for surface EDMed with stationary electrode is $(10.6,12.4,13.2) \mu \mathrm{m}$, with average of $12.06 \mu \mathrm{m}$, while the surface EDMed with rotary electrode has the average of $10.06 \mu \mathrm{m}$ from the three measurements of $(9.8,10.2,10.2) \mu \mathrm{m}$.
Fig. 2: SEM photographs of recast layer thickness on workpiece for: (a) stationary electrode; (b) rotary electrode; (c) combination of V $120 \mathrm{~V}, \mathrm{~N}$ $1000 \mathrm{rpm}$ and $\mathrm{f} 4 \mu \mathrm{m} \mathrm{sec}^{-1}$; (d) combination of $\mathrm{V} 80 \mathrm{~V}, \mathrm{~N} 1500 \mathrm{rpm}$ and $\mathrm{f} 4 \mu \mathrm{m} \mathrm{sec}^{-1}$

Table 3: Comparison of recast layer thickness on workpiece EDMed with stationary and rotary electrode

\begin{tabular}{|c|c|c|c|c|}
\hline \multirow{2}{*}{\multicolumn{2}{|c|}{ Parameter }} & \multicolumn{3}{|c|}{ Recast layer thickness } \\
\hline & & \multirow{2}{*}{$\begin{array}{l}\text { Stationary } \\
\text { electrode }\end{array}$} & \multirow{2}{*}{$\begin{array}{l}\text { Rotary electrode } \\
(\mathrm{N}=500 \mathrm{rpm})\end{array}$} & \multirow{2}{*}{$\begin{array}{l}\text { Percentage } \\
\text { improved }\end{array}$} \\
\hline $\mathrm{V}$ & $\mathrm{f}\left(\mu \mathrm{m} \mathrm{sec}{ }^{-1}\right)$ & & & \\
\hline 80 & 4 & 12.06 & 10.06 & 16.58 \\
\hline
\end{tabular}

Table 4: Comparison of recast layer thickness on workpiece EDMed with the combination of low voltage and high rpm (V 80, N 1500 and $\mathrm{f} 4 \mu \mathrm{m} \mathrm{sec}{ }^{-1}$ ) and high voltage and low rpm (V 120, N $1000 \mathrm{rpm}$ and $\mathrm{f} 4 \mu \mathrm{m} \mathrm{sec}^{-1}$ )

\begin{tabular}{lllll}
\hline $\mathrm{V}$ & $\mathrm{N}(\mathrm{rpm})$ & $\mathrm{f}\left(\mu \mathrm{m} \mathrm{sec}^{-1}\right)$ & $\begin{array}{l}\text { Recast layer } \\
\text { thickness }(\mu \mathrm{m})\end{array}$ & $\begin{array}{l}\text { Percentage } \\
\text { improved }\end{array}$ \\
\hline 80 & 1500 & 4 & 5.7 & 36.66 \\
120 & 1000 & 4 & 9.0 & \\
\hline
\end{tabular}

It is also observed from Table 2 that the highest and lowest recast layer thickness obtained $9 \mu \mathrm{m}$ and $5.7 \mu \mathrm{m}$ at the combination of $\mathrm{V} 120 \mathrm{~V}, \mathrm{~N} 1000 \mathrm{rpm}$ and $\mathrm{f} 4 \mu \mathrm{m} \mathrm{sec} \mathrm{se}^{-1}$ (Run 3 of Table 2) and the combination of V $80 \mathrm{~V}, \mathrm{~N} 1500 \mathrm{rpm}$ and f $4 \mu \mathrm{m} \mathrm{sec}^{-1}$ (Run 11 of Table 2) respectively which are shown in Fig. 2c and d.

It is found that electrode rotation reduces recast layer thickness of about $16.58 \%$ (Table 3) than that of stationary electrode with same voltage and feed rate. It is also observed that within the design space, the combination of low voltage and high $\mathrm{rpm}(\mathrm{V}$ 80, $\mathrm{N}$ 1500 and $\mathrm{f} 4 \mu \mathrm{m} \mathrm{sec}{ }^{-1}$ ) (Run 11 of Table 2) improves the recast layer thickness $36.66 \%$ (Table 4) than that of high voltage and low rpm (V 120, N $1000 \mathrm{rpm}$ and $\mathrm{f}$ $4 \mu \mathrm{m} \mathrm{sec}^{-1}$ ) (Run 3 of Table 2). 
The higher recast layer thickness recorded for the workpiece is as a result of increase in material removal rate. It can be observed that the recast layer thickness is influenced by the voltage, as the voltage increases; recast layer equally increases as a result of more MRR. The more material is removed; the more is the proportion of it that is solidified as recast layer on the machined surface. This is explained by the fact that the amount of molten metal which can be flushed away by the dielectric is constant. Therefore, as more heat is transferred into the material as the voltage increases, the dielectric is increasingly unable to clear away the molten material and so it builds up upon the surface of the workpiece. During cooling, this molten material resolidifies to form the recast layer. On the contrary, as rpm increases, the flushing rate of dielectric increases which prevents the debris to concentrate on the parent metal. Therefore, thinner layer is formed.

Analysis of material migration: The surface morphology of EDMed surface is usually rough as a result of non-uniform distribution of spherical and nonspherical agglomerates. Scanning Electron Microscope/Energy Dispersive X-ray (SEM/EDX) composition analysis of workpiece show the presence of metal particles other than the base metal. The metal particles moving from electrode to workpiece during EDM are flushed out by continuous flow of dielectric fluid. Since the particles cannot be completely flush out of spark gap, part of these materials is deposited on the surface of the workpiece. This implies that during EDM, a significant amount of material is transferred from electrode to the workpiece surface. The composition of elements on the workpiece and electrode surfaces was examined by Quantitative Energy Dispersive X-ray (EDX). In this experimental work, the material migration was first investigated using stationary and rotary electrode with same voltage and feed rate parameters of $80 \mathrm{~V}$ and $4 \mu \mathrm{m} \mathrm{sec}{ }^{-1}$ respectively to compare the two effects. Furthermore, the combined effect of machining parameters on material migration was examined by analyzing all workpiece surfaces which were EDMed with different combination of process parameters provided by DOE. The results of the EDX analysis showing the percentage elements migrated from the electrode to the workpiece are shown in Table 2 and Fig. 3 respectively.

Results of the EDX analysis show that appreciable amount of Carbon (C) and Copper $(\mathrm{Cu})$ are found to migrate to the surface of the workpiece. It is observed that 5.97 and $0.18 \%$ of $\mathrm{C}$ and $\mathrm{Cu}$ respectively were migrated to the surface EDMed with rotary electrode (Fig. 3b) which is less than that of the surface EDMed with stationary electrode $(6.55 \% \mathrm{C}$ and $0.45 \% \mathrm{Cu})$ (Fig. 3a). Therefore, it seems that electrode rotation helps to reduce the material migration on the workpiece surface.

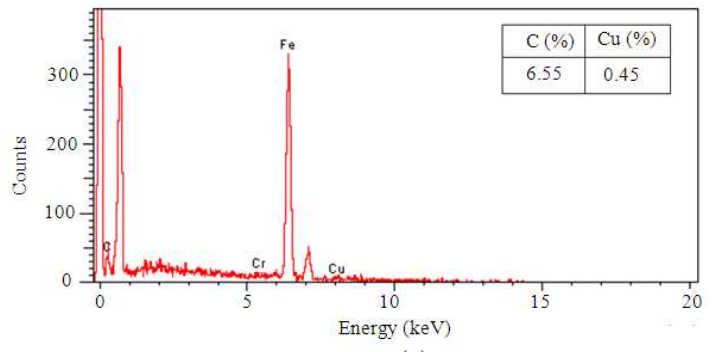

(a)

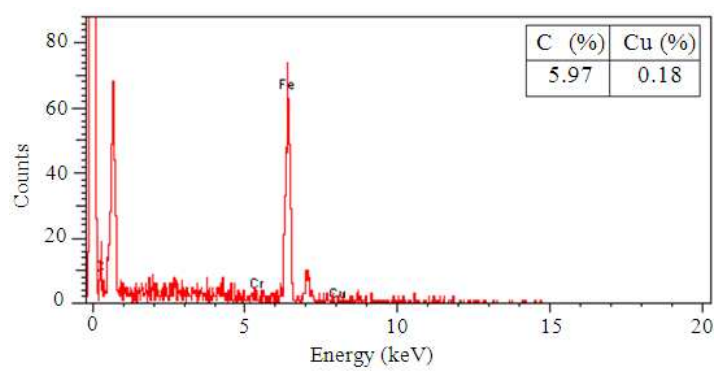

(b)

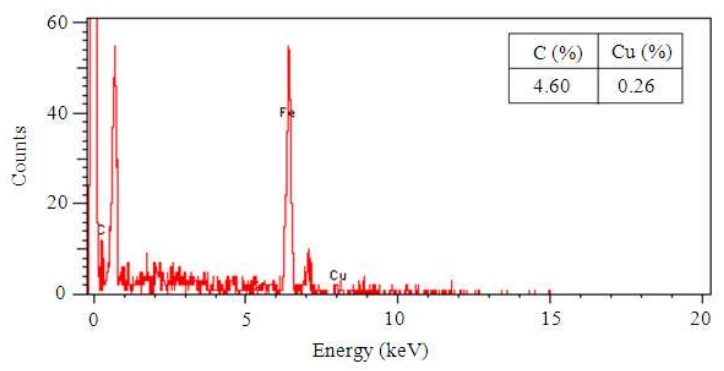

(c)

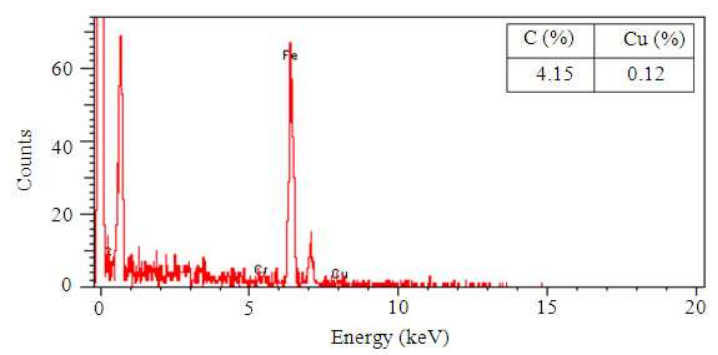

(d)

Fig. 3: Migration of $\mathrm{C}$ and $\mathrm{Cu}$ from electrode to workpiece surface with: (a) stationary electrode; (b) rotary electrode; (c) combination of high voltage and low rpm; (V 133.64V, N $1000 \mathrm{rpm}$ and f $5 \mu \mathrm{m} \mathrm{sec}^{-1}$ ); (d) combination of low voltage and high rpm; (V $80 \mathrm{~V}, \mathrm{~N}$ $1500 \mathrm{rpm}$ and $\mathrm{f} 6 \mu \mathrm{m} \mathrm{sec}^{-1}$ ) 
Am. J. Engg. \& Applied Sci., 3 (2): 396-402, 2010

Table 5: Comparison of material migration on workpiece EDMed with stationary and rotary electrode

\begin{tabular}{|c|c|c|c|c|c|c|}
\hline \multirow{3}{*}{\multicolumn{3}{|c|}{ Parameter setting }} & \multicolumn{4}{|c|}{ Material migration } \\
\hline & & & \multicolumn{4}{|l|}{$\mathrm{C}(\%)$} \\
\hline & & & \multirow{2}{*}{\multicolumn{2}{|c|}{$\begin{array}{l}\text { Stationary } \\
\text { Electrode }\end{array}$}} & \multirow{2}{*}{\multicolumn{2}{|c|}{$\begin{array}{l}\text { Rotary electrode } \\
(\mathrm{N}=500 \mathrm{rpm})\end{array}$}} \\
\hline $\mathrm{V}$ & \multicolumn{2}{|c|}{$\left.\mathrm{f}(\mu \mathrm{m} \mathrm{sec})^{-1}\right)$} & & & & \\
\hline 80 & 4 & & \multicolumn{2}{|l|}{6.55} & \multicolumn{2}{|l|}{5.97} \\
\hline \multicolumn{7}{|c|}{$\begin{array}{l}\text { Table 6: Comparison of material migration on workpiece EDMed } \\
\text { with the combination of high voltage and low rpm (V } \\
\left.133.64 \mathrm{~V}, \mathrm{~N} 1000 \mathrm{rpm} \text { and } 5 \mu \mathrm{m} \mathrm{sec}^{-1}\right) \text { and low voltage and } \\
\text { high rpm }\left(\mathrm{V} 80 \mathrm{~V}, \mathrm{~N} 1500 \mathrm{rpm} \text { and } 6 \mu \mathrm{m} \mathrm{sec}^{-1}\right)\end{array}$} \\
\hline & & & \multicolumn{2}{|c|}{$\begin{array}{l}\text { Material } \\
\text { migration }\end{array}$} & \multicolumn{2}{|c|}{$\begin{array}{l}\text { Percentage } \\
\text { improved }\end{array}$} \\
\hline $\mathrm{V}$ & $\mathrm{N}(\mathrm{rpm})$ & $\left.\mathrm{f}(\mu \mathrm{m} \mathrm{sec})^{-1}\right)$ & $\mathrm{C}(\%)$ & $\mathrm{Cu}(\%)$ & $\mathrm{C}(\%)$ & $\mathrm{Cu}(\%)$ \\
\hline 133.64 & 1000 & 5 & 4.60 & 0.26 & 9.78 & 53.84 \\
\hline 80 & 1500 & 6 & 4.15 & 0.12 & & \\
\hline
\end{tabular}

It is also observed from Table 2 that the lowest percentage of material migration $(4.15 \mathrm{C}$ and $0.12 \%$ $\mathrm{Cu}$ ) from electrode to workpiece was found at Run 4 of Table 2 with parameter combination of $\mathrm{V}=80 \mathrm{~V}$, $\mathrm{N}=1500$ and $\mathrm{f}=6 \mu \mathrm{m} \mathrm{sec} \sec ^{-1}$ (Fig. 3d), while the highest percentage of material migration $(4.60 \mathrm{C}$ and $0.26 \% \mathrm{Cu}$ ) (Fig. 3c) was found at Run 15 of Table 2 with parameter combination of $\mathrm{V}=133.64 \mathrm{~V}, \mathrm{~N}=1000$ and $\mathrm{f}=5 \mu \mathrm{m} \mathrm{sec}^{-1}$.

The presence of $\mathrm{C}$ on workpiece surface is as a result of decomposition of hydrocarbon of dielectric fluid and alloying with the workpiece. It is found that migration of $\mathrm{C}$ and $\mathrm{Cu}$ on the workpiece surface reduce $8.8 \%$ and $60 \%$ respectively (Table 5 ) when using rotary electrode instead of stationary electrode with same parameters setting. The result of surfaces EDMed with stationary electrode having higher percentage of material element migrated to workpiece surfaces could be as a result of more heat is confined in the vicinity of both electrode and workpiece. Since temperature as a result of heat promotes reaction, hence more diffusion of material elements takes place between the interfacial metals. This heat promotes reaction between the two electrodes particles, thereby increasing material diffusion into both workpiece and electrode surface during the EDM with stationary electrode.

Further EDX analysis with different combination of process parameters shows that the combined parameter setting of $\mathrm{V} 80 \mathrm{~V}, \mathrm{~N} 1500 \mathrm{rpm}$ and $\mathrm{f}$ $6 \mu \mathrm{m} \mathrm{sec}^{-1}$ reduces the migration of $\mathrm{Cu}$ to workpiece by $53.84 \%$ than that of the parameter setting of $\mathrm{V}$ $133.64 \mathrm{~V}, \mathrm{~N} 1000 \mathrm{rpm}$ and f $5 \mu \mathrm{m} \mathrm{sec}{ }^{-1}$ (Table 6). From the EDX analysis it is further revealed that the migration of elements from electrode to workpiece is influenced by the voltage, as the voltage increases material migration equally increases (Fig. $3 \mathrm{c}$ and d). This is because, increase in voltage increases spark energy, therefore, more metal is melted from the electrodes which can not be completely flushed away by the dielectric fluid. On contrary, the EDX analysis showed that higher $\mathrm{rpm}$ reduces the percentage of material migration (Fig $3 \mathrm{c}$ and d). Higher rpm increases the flushing rate of dielectric which helps in preventing the debris to concentrate on the parent metal. Therefore, material transfer is reduced.

\section{CONCLUSION}

In this research, the influence of process parameters on surface integrity during EDM milling has been investigated. The machining parameters used for this experiment were voltage, rotational speed of the electrode and feed rate. The various surface features such as recast layer thickness, micro cracks and material migration have been thoroughly investigated. The following conclusions can be drawn from the study:

- From the obtained test results it is evident that voltage and rotational speed of electrode significantly influence various criteria of surface integrity such as recast layer thickness, surface crack and material migration

- Electrode rotation reduces the number of micro cracks on the workpiece surface compare to that of stationary electrode. Besides, the effect of micro crack is less on the workpiece surface when the combination of reasonably low voltage and high $\mathrm{rpm}\left(\mathrm{V} 80 \mathrm{~V}, \mathrm{~N} 1500 \mathrm{rpm}\right.$ and $\left.\mathrm{f} 6 \mu \mathrm{m} \mathrm{sec}^{-1}\right)$ is used compare to that of high voltage and low rpm (V $120 \mathrm{~V}, \mathrm{~N} 1000 \mathrm{rpm}$ and $\mathrm{f} 6 \mu \mathrm{m} \mathrm{sec}^{-1}$ )

- The recast layer thickness obtained during the EDM milling of stainless steel with rotary electrode achieved $16.58 \%$ improvement over the recast layer thickness obtained with stationary electrode. Furthermore, within the design space, the combination of low voltage and high rpm (V $80 \mathrm{~V}, \mathrm{~N} 1500$ and f $4 \mu \mathrm{m} \mathrm{sec}^{-1}$ ) improves the recast layer thickness $36.66 \%$ than that of high voltage and low rpm (V $120 \mathrm{~V}, \mathrm{~N} 1000 \mathrm{rpm}$ and $\left.\mathrm{f} 4 \mu \mathrm{m} \mathrm{sec}^{-1}\right)$ 
- Migration of $\mathrm{C}$ and $\mathrm{Cu}$ on the workpiece surface reduces 8.8 and $60 \%$ respectively when using rotary electrode instead of stationary electrode with same parameters setting. The combination of reasonably low voltage and high $\mathrm{rpm}$ reduces material migration and minimizes the surface contamination on workpiece surface during EDM milling of stainless steel

\section{REFERENCES}

Abu Zeid, O.A., 1997. On the effect of electro discharge machining parameters on the fatigue life of AISI D6 tool steel. J. Mater. Proc. Technol., 68: 27-32. DOI: 10.1016/S09240136(96)02523-X

Bayramoglu, M. and A.W. Duffill, 1994. Systematic investigation on the use of cylindrical tools for the production of 3D complex shapes on CNC EDM machines. Int. J. Mach. Tools Manufact., 34: 327339. DOI: 10.1016/0890-6955(94)90003-4

Bhattacharyya, B., S. Gangopadhyay and B.R. Sarkar, 2007. Modeling and analysis of EDMed job surface integrity. J. Mater. Proc. Technol., 189: $169-177 . \quad$ DOI: 10.1016/j.jmatprotec.2007.01.018

Caydas, U. and A. Hascalik, 2007. Electrical discharge machining of Titanium alloy (Ti-6Al-4V). Applied Surface Science. 253: 9007-9016. DOI: 10.1016/j.apsusc.2007.05.031

Ho, K.H. and S.T. Newman, 2003. State of the art Electrical Discharge Machining (EDM). Int. J. Mach. Tools Manufact., 43: 1287-1300. DOI: 10.1016/S0890-6955(03)00162-7
Kruth, J.P., L. Stevens, L. Froyen and B. Lauwers, 1995. Study on the white layer of a surface machined by die sinking electro discharge machining. Annals CIRP, 44: 169-172. DOI: 10.1016/S0007-8506(07)62299-9

Kumar, S., R. Singh, T.P. Singh and B.L. Sethi, 2008. Surface modification by electrical discharge machining: A review. J. Mater. Proc. Technol. 209: 3675-3587. DOI: 10.1016/j.jmatprotec.2008.09.032

Lee, H.T. and T.Y. Tai, 2003. Relationship between EDM parameters and surface crack formation. J. Mater. Proc. Technol., 142: 676-683. DOI: 10.1016/S0924-0136(03)00688-5

Lee, L.C., L.C. Lim, V. Narayanan and V.C. Venkatesh, 1988. Quantification of surface damage of tool steels after EDM. Int. J. Mach. Tools Manufact., 28: 359-372. DOI: 10.1016/0890-6955(88)90050-8

Lee, L.C., L.C. Lim, Y.S. Wong and H.H. Lu, 1990. Towards a better understanding of the surface features of electro-discharge machined tool steels. J. Mater. Process. Technol., 24: 513-523. DOI: 10.1016/0924-0136(90)90212-D

Ramasawmy, H. and L. Blunt, 2004. Effect of EDM process parameters on 3D surface topography. J. Mater. Proc. Technol., 148: 155-164. DOI: 10.1016/S0924-0136(03)00652-6

Yu, Z.Y., T. Masuzawa and M. Fujino, 1998. MicroEDM for three dimensional cavities, development of uniform wear method. Annals CIRP, 47: 169172. DOI: $10.1016 / \mathrm{S} 0007-8506(07) 62810-8$ 